\title{
Towards the electronic journal?
}

Recent developments in optical disk technology promise electronic access to whole libraries of scientific journals, but the consequences for the ways in which journals operate are far from clear.

IN major technical innovation, hopes and ambitions lead reality by years, even decades. So much is common experience. From the late 1950s onwards, people have been making public speeches (and organizing conferences at which to make them) on the theme that computer technology would change the world, but two decades went by before it did so. Much the same happened with air transport, technically possible since early this century, but a means of mass transport only after more than half a century. Why should there be these lags? And how is it possible to tell when they are about to end?

Two sets of considerations arise. First, the enthusiasms of the prophets of innovation customarily outstrip what technology will allow. (Arthur C. Clarke, who sang the praises of communications satellites in the 1950 s, was lucky that he had to wait a mere decade to see something of the reality.) Second, and probably more important, the potential beneficiaries of innovations tend to stick to their oldfashioned ways in the face of all the evidence that change would be beneficial.

The same two influences explain why the late J. D. Bernal's dream that the scientific literature would be organized so that its elements could be directed exclusively towards those with particular interests in them has been on the shelf for more than four decades: the technology has been inadequate and the users indifferent.

But revolution is now in the air. There has been no single change of attitudes, nor single improvement of technology, to account for what is happening. Rather, a dozen different changes, and the prospect of more ahead, has given the notion of the electronic journal (more strictly, journalcomplex) the promise of reality.

Technology is the sine qua non, and has markedly improved. This page of Nature will hold roughly 7,250 bytes of information when it is complete. (The figure is not exact because printed characters differ in width.) The whole of a weekly issue's text would fit comfortably into a megabyte of computer storage. But it is only in the past two years or so that information storage of that magnitude could be had at a reasonable price. And even now, storing a year's issues of this journal in a conventional computer store would be an extravagant proposition; even from a mail-order address, a 50 megabyte hard disk would cost the best part of $\$ 1,000$.

Optical disks have changed all that.
Devices not much more sophisticated than those sold in audio-record retail shops will hold 500 megabytes, enough for a decade of Nature. True, these disks are 'read-only' disks, but who wants an archive that can be rewritten by its users? The same device could be used to put out weekly issues of 500 different weekly publications of roughly the same extent as this. The problem of storing information has been solved, it may appear.

This is the present inspiration of the Adonis project by which a consortium of European publishers (Blackwells, Elsevier, Pergamon and Springer) plans to start next year distributing to subscribers a weekly issue of an optical disk carrying the stored images of pages from the current issues of more than 400 scientific journals. Already, the plan embodies elements of Bernal's vision of a user-directed system of document supply. The first customers will be the libraries at pharmaceutical companies' research centres; the journals to be distributed will be chosen appropriately.

Adonis differs from a legion of earlier schemes in the assurance one has that it will function well. The consortium has just emerged from a two-year trial with just over 200 journals, distributed on optical disks to a handful of libraries around the world, which has tested the latest somewhat technically extravagant version of the technology. The image of each page of a journal is represented in facsimile, not by character-coding, as the stream of bits of information arising when the image is scanned at specified resolution. 'Bitmapping' is the word.

Two obvious advantages are that the system will reproduce pages from particular journals with exactly the appearance they have in printed form, and that it will handle illustrations, even photographs. In practice, it is planned to scan text with a horizontal resolution of 300 picture elements per inch and a vertical resolution half as fine; that should deal well with characters a third as high as those on this page. The vertical resolution of the scanning of photographic illustrations will be twice as fine as that for text.

Fears that the simple-minded scanning of printed pages will use enormous quantities of storage have been dispelled by clever software. The system is smart enough not to store the results of scanning with white spaces, but allows the decoding system to reconstruct them. No doubt it is only a matter of time before charactercoding and bit-mapping are mixed in a bastard system, but meanwhile it is feasible to include more than 5,000 typical pages from scientific journals on a single disk with some assurance that their contents can be accurately recovered as computer images or even as hard copy.

But what value is an optical disk embodying the equivalent of more than a year's supply of Nature if its contents are not self-evident? None at all, of course. So Adonis has been working at the design of an index that will allow users not merely to reconstruct its contents but also to allow individuals to select the items likely to be of interest in their research. 'Research profile' is the buzz-word.

Will it work? Adonis is naturally confident. Technically, there seems little doubt. But how will potential customers respond? After two decades of thumbing through Current Contents, marking up (for reprint requests) an appropriate version as if it were a racecard, and similar experience of the databases of the US Library of Congress and the American Chemical Society, one senses that there is a generation of researchers whose need of information is menu-driven. If (as Adonis hopes) a researcher's profile is instantly requited by laser printout, reactions may be much more favourable than in the past. Bernal's dream may be coming true.

But will it also be a nightmare? Technically, it will be a jungle; Adonis is not the only commercial enterprise in the field, while it is improbable that non-profit organizations such as the American Chemical Society and the US Library of Congress (which has been patiently experimenting for the past five years) will allow themselves to be left behind. Then there lies ahead the whole multimedia technology, whose broadband communication systems may supersede disks that must be physically transferred from place to place.

Intellectually, it is not a pleasing prospect that the distinctive identities of journals will inevitably - not quickly, but in the course of time - be subsumed in the identity of their carrier, the purveyor of the disks. Amalgamation into megajournals is a likely outcome, but what will authors think of that? Browsing may not die off, but will have to be pre-planned. That is why it must be hoped that there will always be some ink-on-paper journals.

John Maddox 